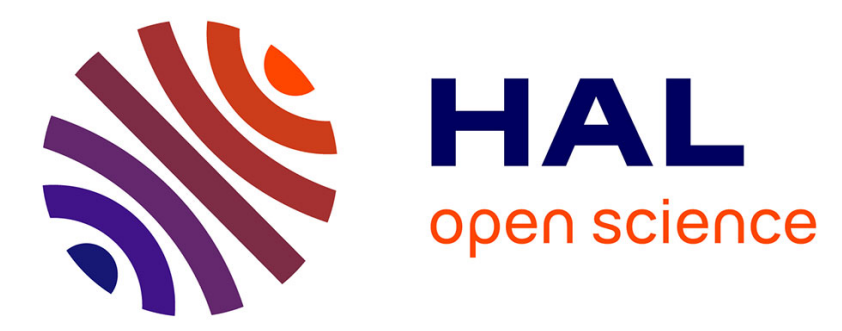

\title{
Passive or simulated displacement of one arm (but not its mirror reflection) modulates the involuntary motor behavior of the other arm
}

C. Brun, M. Metral, M. Chancel, A. Kavounoudias, M. Luyat, Michel Guerraz

\section{- To cite this version:}

C. Brun, M. Metral, M. Chancel, A. Kavounoudias, M. Luyat, et al.. Passive or simulated displacement of one arm (but not its mirror reflection) modulates the involuntary motor behavior of the other arm.

Neuroscience, 2015, 285, pp.343 - 355. 10.1016/j.neuroscience.2014.11.036 . hal-01419386

\section{HAL Id: hal-01419386 \\ https://hal.science/hal-01419386}

Submitted on 19 Dec 2016

HAL is a multi-disciplinary open access archive for the deposit and dissemination of scientific research documents, whether they are published or not. The documents may come from teaching and research institutions in France or abroad, or from public or private research centers.
L'archive ouverte pluridisciplinaire HAL, est destinée au dépôt et à la diffusion de documents scientifiques de niveau recherche, publiés ou non, émanant des établissements d'enseignement et de recherche français ou étrangers, des laboratoires publics ou privés. 


\section{PASSIVE OR SIMULATED DISPLACEMENT OF ONE ARM (BUT NOT ITS MIRROR REFLECTION) MODULATES THE INVOLUNTARY MOTOR BEHAVIOR OF THE OTHER ARM}

\author{
C. BRUN, ${ }^{a}$ M. METRAL, ${ }^{a, b}$ M. CHANCEL, ${ }^{a, c}$ \\ A. KAVOUNOUDIAS, ${ }^{\mathrm{C}}$ M. LUYAT ${ }^{\mathrm{b}}$ AND M. GUERRAZ ${ }^{\mathrm{a}}$ * \\ a Univ. Savoie, LPNC, F-7300 UMR 5105 Chambéry, CNRS, France \\ ${ }^{\mathrm{b}}$ Univ. Lille 3, Laboratory of Functional Neurosciences and \\ Pathologies, EA 4559, Villeneuve d'Ascq, France \\ ${ }^{\mathrm{c}}$ Aix-Marseille Univ. CNRS, LNIA UMR 7260, Marseille, France
}

\begin{abstract}
Recent studies of both healthy and patient populations have cast doubt on the mirror paradigm's beneficial effect on motor behavior. Indeed, the voluntary arm displacement that accompanies reflection in the mirror may be the determining factor in terms of the motor behavior of the contralateral arm. The objective of the present study was to assess the respective effects of mirror reflection and arm displacement (whether real or simulated) on involuntary motor behavior of the contralateral arm following sustained, isometric contraction (Kohnstamm phenomenon). Our results revealed that (i) passive displacement of one arm (displacement of the left arm via a motorized manipulandum moving at $4 \%$ s) influenced the velocity of the Kohnstamm phenomenon (forearm flexion occurring shortly after the cessation of muscle contraction) in the contralateral arm and (ii) mirror vision had no effect. Indeed, the velocity of the Kohnstamm phenomenon tended to be adjusted to match the velocity of the passive displacement of the other arm. In a second experiment, arm displacement was simulated by vibrating the triceps at 25,50 or $75 \mathrm{~Hz}$. Results showed that the velocity of the Kohnstamm phenomenon in one arm increased with the vibration frequency applied to the other arm. Our results revealed the occurrence of bimanual coupling because involuntary displacement of one arm was regulated by muscle-related information generated by the actual or simulated displacement of the other arm. In line with the literature data on voluntary motor behavior, our study failed to evidence an additional impact of mirror vision on involuntary motor behavior. (C) 2014 IBRO. Published by Elsevier Ltd. All rights reserved.
\end{abstract}

Key words: mirror paradigm, bimanual coupling, Kohnstamm phenomenon, muscular afferents.

\footnotetext{
${ }^{*}$ Corresponding author. Address: Laboratory of Psychology and NeuroCognition, UMR 5105 CNRS - University of Savoie, BP 1104, 73011 Chambery Cedex, France. Tel: + 33-4-79-75-91-86; fax: + 33-4-79-75-85-99.

E-mail address: Michel.guerraz@univ-savoie.fr (M. Guerraz).

Abbreviations: ANOVA, analysis of variance; iEMG, integrated EMG values; MVC, maximum voluntary contraction.
}

\section{INTRODUCTION}

Over the last 10 years, the mirror paradigm has been considered as a treatment option for restoring brain function in general (Rosen and Lundborg, 2005; Dohle et al., 2009; Ramachandran and Altschuler, 2009) and promoting recovery from hemiparesis and hemiplegia in particular. In this mirror paradigm, the participant sits in front of a mirror oriented parallel to the body midline, with its reflective surface facing one limb and blocking the view of the other. When looking into the mirror, the participant sees the reflection of one limb which position coincides with that of the other (unseen) limb. This arrangement can create vivid visual illusions whereby movement of an intact limb in hemiparetic patients may be perceived as affecting the paretic (unseen) limb. However, after early enthusiasm for mirror therapy, the true benefit of this approach (notably when compared with therapies such as bimanual coupling) in recovery from hemiparesis is now being questioned (for a review, see Rothgangel et al., 2011).

Metral et al. (2014) recently assessed the mirror paradigm's role in the motor control of bimanual coordination tasks performed by healthy participants during sensorimotor disturbance in four visual conditions (i) mirror vision (i.e. with the non-dominant arm reflected in a mirror and the dominant arm hidden), (ii) full vision (i.e. both arms visible), (iii) with only the non-dominant arm visible and (iv) with the eyes closed. The participants were required to produce synchronous movements of both arms while sensorimotor disturbance was applied to their dominant arms (co-vibration of antagonistic muscles - the biceps and the triceps). This disturbance substantially decreased the sensitivity of position perception (Roll et al., 1989; Bock et al., 2007) and altered the subject's ability to perform coordinated visuomotor or postural tasks (Gilhodes et al., 1986; Oullier et al., 2009) and bimanual coupling, that is, coupling between the two hands constrained in spatial or temporal terms (Swinnen, 2002; Swinnen et al., 2003). Although mirror reflection of one arm can induce consistent, vivid, perceptual illusions (Holmes et al., 2004; Zampini et al., 2004; Mercier and Sirigu, 2009; Ramachandran and Altschuler, 2009; Guerraz et al., 2012; Metral et al., 2013), Metral et al.'s (2014) results confirmed that mirror vision is not highly effective in modulating voluntary motor behavior. Indeed, although performance in synchronous movements was higher in the condition of mirror vision as compared to vision of only 
the non-dominant arm, the motor performance was no better in the mirror vision condition than in the eyesclosed condition - regardless of whether or not sensorimotor disturbance was applied. In contrast, full vision of the two hands facilitated synchronous movements in the condition of sensorimotor disturbance.

The fact that it is difficult to demonstrate mirror vision's impact on voluntary, bimanual, coordinated movements does not imply that mirror vision has no effect (or a limited effect) on motor control as a whole. Hence, the objective of the present study was to further investigate the mirror paradigm's impact on motor control in the context of involuntary (rather than voluntary) motor behavior. After performing an intense, long-lasting, isometric muscle contraction, involuntary movements may occur as a consequence of post-contraction muscle activity (Craske and Craske, 1986; Gurfinkel and Levick, 1989; Ghafouri et al., 1998; Ivanenko et al., 2006; Duclos et al., 2007). This phenomenon was first described by Kohnstamm in 1915. It can be easily experienced by strongly pushing or pulling with the arms against a fixed support for half a minute. Shortly after the cessation of isometric muscle contraction, the arms rise slowly and involuntarily - giving a feeling of lightness. This phenomenon is thought to be related to both peripheral components (increased afferent inflow after sustained contraction; see Gregory et al., 1987; Hagbarth and Nordin, 1998) and central components (prolonged excitation of central structures; see Duclos et al., 2007). Dissociating actual and perceived body position (and therefore manipulating body representation) has been shown to modulate this involuntary motor behavior. Wells (1944) used the Kohnstamm phenomenon (which can also occur in the legs) to demonstrate the influence of somesthetic inputs from the neck on limb muscles in humans and showed that the extension of the knee joints following sustained isometric contraction becomes asymmetric when the head is turned toward one shoulder. Interestingly, Gurfinkel and Levick (1991) showed that modulation of the Kohnstamm phenomenon occurred regardless of whether the head's postural changes were actual or only perceived; dissociation was achieved by vibration of neck muscles, hypnosis or use of a return phenomenon. Considering that the mirror paradigm is an easy way to dissociate actual and perceived arm position, we set out to modulate the Kohnstamm phenomenon in one arm (the right arm) by using a mirror to provide participants with a false visual representation of that arm. After a long-lasting isometric contraction of the biceps of the right (unseen) arm, participants were required to look at their left arm and its reflected image through a mirror positioned in the sagittal plane. The left arm was either static or moved passively by a motorized manipulandum.

The results of this first experiment (referred to as Experiment 1) revealed that (i) passive displacement of the left arm clearly modulated the kinematics of the involuntary right arm displacement following effort (i.e. Kohnstamm phenomenon) and (ii) unexpectedly, mirror manipulation had no additional effect. To determine whether proprioceptive input generated by passive displacement of the left arm might be responsible for the modulation of the contralateral post-contraction, a second experiment was performed. Passive disp lacement of the left arm was replaced by simulated displacement of that same arm via the use of vibratory stimulation (Goodwin et al., 1972; Gilhodes et al., 1986). Our results showed that vibratory simulation of arm movement modulated the kinematics of the Kohnstamm phenomenon in the same way as passive displacement did.

\section{EXPERIMENTAL PROCEDURES OF EXPERIMENT 1}

\section{Participants}

Twelve participants ( 7 females and 5 males; mean (SD) age $=22.1$ (2.3) years) took part in Experiment 1. All but one were right-handed (as determined in the Edinburgh Inventory Test - Oldfield, 1971). As reported in the literature, some individuals do not show the Kohnstamm phenomenon (Craske and Craske, 1986; Gurfinkel and Levick, 1991; Ivanenko et al., 2006), and so we screened the participants for the Kohnstamm phenomenon in a preliminary experiment. Twelve of the 17 screened participants displayed the Kohnstamm phenomenon on the first application and therefore took part in Experiment 1. None of the 12 volunteers had a history of visual, proprioceptive or neuromuscular disease, and all provided their prior, written, informed consent to participation in the experiment. The experiment was performed in accordance with the tenets of the Declaration of Helsinki and the study protocol had been approved by the local independent ethics comity (Ethics comity LLSH, Chambery, France).

\section{Material}

Participants sat in front of a large, custom-built box. Depending on the experimental conditions, either an opaque board (measuring 65 by $65 \mathrm{~cm}$ and preventing the participant from directly viewing his/her right hand) or a mirror (measuring 65 by $65 \mathrm{~cm}$ ) with the reflective surface facing toward the participant's left was positioned vertically in the middle of the box and was oriented parallel to the participant's mid-sagittal plane. The participants' forearms were positioned on each side of the mirror (or opaque board) and were held by two manipulanda devices (wooden arms on which subjects placed their forearms and hands) positioned at $30^{\circ}$ to the horizontal in the starting position (Fig. 1). The distances between the manipulanda and the mirror were adjusted so that the mirror image of the left arm coincided with the position of the right arm. The right manipulandum was fixed, whereas the left manipulandum was motorized (with a low-noise direct current motor) and could rotate (via a remote controller) to flex the participant's left elbow joint. The participant's forearms were adjusted on the manipulandum so that the axis of motorized rotation coincided exactly with the elbow joint. 

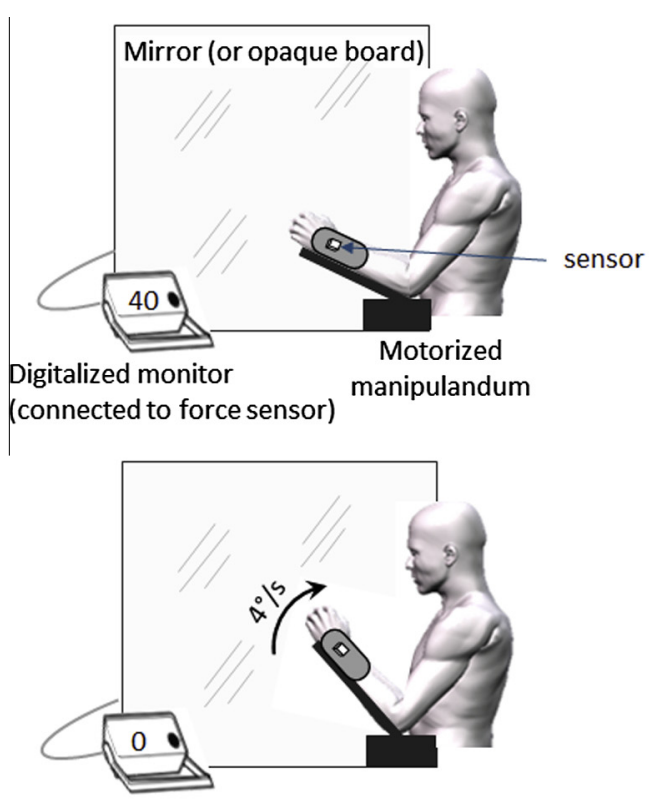
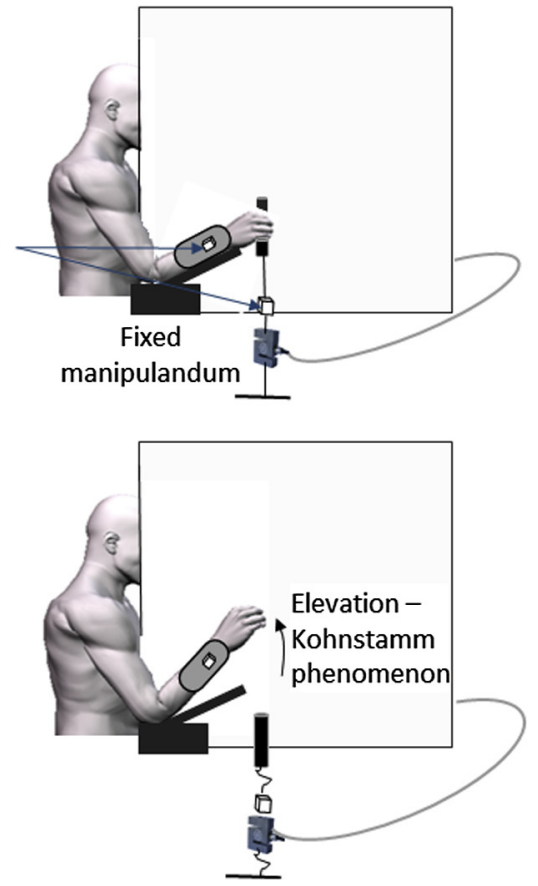

Phase 1 : Isometric contraction (35s)

Phase 2 : Post-contraction ( $10 \mathrm{~s})$

Fig. 1. The experimental setup. The participant sat at a table facing a box which was compartmentalized by a mirror reflecting the image of his/her left arm. This mirror could be covered, depending on the experimental condition. The manipulandum supporting the left arm was motorized and could flex the arm at the elbow joint at a velocity of $4 \%$. With their right hand, the participant pulled on a handle fixed to a force sensor (in phase 1 ) with a constant, isometric force of approximately $40 \%$ of the MVC for $35 \mathrm{~s}$. In phase 2 , the participant stopped pulling, let go of the handle and was not meant to resist any involuntary arm displacements.

In order to avoid wrist movements, participants wore splints on each hand. Displacements of the forearms were recorded with an electromagnetic motion capture system (Polhemus Fastrak ${ }^{\mathrm{TM}}$, Colchester, VT). A sensor was positioned on each splint, so that continuous data on the two forearms' angles were provided. A third sensor was positioned on the handle used to measure isometric forces in the contraction period; it detected the moment when the participant let go of the handle following the contraction period. Data were sampled at a frequency of $30 \mathrm{~Hz}$.

To ensure that muscle activity during the contraction period was similar under the different experimental conditions, EMG activities of the biceps and triceps brachii of the right arm were recorded. Surface electrodes were placed $3 \mathrm{~cm}$ apart longitudinally over the bellies of the muscles. A reference electrode was attached to a body area far from the studied muscles. The EMG data were sampled at $1000 \mathrm{~Hz}$ with a Biopac device (Biopac Systems Inc., CA, United States).

\section{Procedures}

To evoke the Kohnstamm phenomenon (i.e. involuntary motor behavior) in the right arm, participants held a handle (fixed to a force sensor via a strap: Digital Analyser, Multi-Myometer, MIE Medical Research Ltd., Leeds, UK) with their right hand and pulled on it with a constant, isometric force (at approximately $40 \%$ of the maximum voluntary contraction (MVC) measured prior to the experimental session) for $35 \mathrm{~s}$ (Ivanenko et al.,
2006; Duclos et al., 2007). The exerted force was recorded, digitized and displayed on a monitor positioned on the left side of the custom box. Participants were asked to adjust the force on this basis. After $35 \mathrm{~s}$, participants were told to stop pulling, to focus their visual attention on either the mirror or the opaque board positioned in the sagittal plane and then to gently let go of the handle. Before doing so, they were asked to tilt their head forward and to the left slightly. This ensured that the right arm was out of sight. Participants were told not to resist to any involuntary arm displacements (i.e. Kohnstamm phenomenon).

In half the trials, the participant's left forearm was flexed passively at a constant velocity of $4 \% \mathrm{~s}$ for approximately $10 \mathrm{~s}$ when the participant let go of the handle (following the contraction period). Again, the participants were told not to resist this passive displacement. In the other half of the trials, the left arm was not displaced (static condition).

Two visual conditions were studied: (i) mirror vision: subjects were looking at a mirror image of their left (moving) forearm; in this condition, both the left arm and its reflected image were visible; (ii) no mirror vision: subjects looked at the opaque board and only the left arm was visible. The mirror vision and no mirror vision conditions were paired with the two left arm conditions (passive displacement versus static), giving a total of four experimental conditions in a factorial, within-subjects design. Each condition was repeated 4 times in pseudorandom order, giving a total of 16 trials per participant. To limit fatigue, a rest period of approximately $3 \mathrm{~min}$ 
was imposed after each trial and an additional rest period of 5 min was imposed after every four trials. Participants were also required to actively and synchronously flex and extend both arms between trials. Indeed, it has been found that involuntary post-contraction is canceled or strongly decreased after active movements of the corresponding joint (Hutton et al., 1987; Duclos et al., 2007).

\section{Data analysis}

Velocity of the right and left arms. In each trial, the velocity (in $\%$ ) of the right arm's displacement was calculated from the moment at which the participant let go of the handle until the arm reached its maximum angular amplitude (up to $45^{\circ}$ from the initial position). Passive displacement of the left arm was measured over the same period of time. The velocity of the Kohnstamm phenomenon was then normalized (as an absolute difference) by reference to the velocity of the passively moved left arm (normalized velocity $=$ abs[velocity of the Kohnstamm phenomenon in $\%-4 \%$ s]). The normalized velocity was therefore null when the right arm moved at $4 \%$ (the velocity of passive displacement of the other arm). The normalized velocity was used because the Kohnstamm phenomenon can be either slower or faster than the passive displacement of the left arm (4\%).

Integrated EMG activity. Recorded EMG data were band-pass filtered between 10 and $500 \mathrm{~Hz}$, rectified and smoothed by a moving average (30 data points, $30 \mathrm{~ms}$ ). Mean integrated EMG values (iEMG) for each trial were calculated during the contraction period (using the trapezoidal rule). The iEMG activity during the contraction period was calculated as a percentage of the iEMG activity during MVC of the biceps and triceps brachii. The biceps iEMG activity during the contraction period was similar under all four experimental conditions (mean (SD) $=38(2.1) \%$ of MVC, $F<1 ; p>.05)$. The same was true for the triceps (mean (SD) $=13(0.7) \%$, $F<1 ; p>.05)$.

\section{Statistics}

Kinematic data were analyzed using a $2 \times 2$ [left arm condition ("passive displacement" versus "static") $\times$ vision ("mirror vision" versus "no mirror")] repeated-measures analysis of variance (ANOVA) in a within-subjects design. The threshold for statistical significance was set to $p<.05$.

\section{RESULTS OF EXPERIMENT 1}

\section{The velocity of the Kohnstamm phenomenon}

As can be seen in a representative trial (Fig. 2), the right forearm flexed slowly and involuntarily shortly after cessation of muscle contraction in the right arm. When data from all four experimental conditions were pooled, the mean (SD) velocity of the Kohnstamm phenomenon was $6.7(6.1)^{\circ} \%$ s. As shown in Table 1, the mean velocity of the Kohnstamm phenomenon in the mirror vision condition was similar to that observed in the absence of mirror vision in both the passive displacement condition $(5.8 \% \mathrm{~s}$ and $5.7 \% \mathrm{~s}$ for mirror and no-mirror trials, respectively) and the static condition $(7.9 \%$ s and $7.5 \%$ s, respectively).

As shown in Fig. 3, the Kohnstamm phenomenon in the static condition could be either faster or slower than $4 \%$ in individual participants (when data for mirror and no-mirror conditions were pooled). In participants in whom the Kohnstamm phenomenon was faster than $4 \%$ $\mathrm{S}$ in the static condition (participants on the left side of Fig. 3), the phenomenon's velocity was lower when the other arm was moved passively at $4 \% \mathrm{~s}$. In participants in whom the Kohnstamm phenomenon was slower than $4 \% \mathrm{~s}$ in the static condition (participants on the right side of Fig. 3), the phenomenon's velocity was greater when the other arm was moved passively at $4 \%$ s. The velocity of the Kohnstamm phenomenon was therefore adjusted as a function of the velocity of the passively moved arm. In order to test the statistical significance of these results, the following statistical analysis was performed on these normalized values, that is, on the absolute difference of the Kohnstamm phenomenon by reference to the velocity of the passively moved left arm.

\section{Normalized velocity of the Kohnstamm phenomenon}

As mentioned above, the velocity of the Kohnstamm phenomenon in the right arm was (to some extent) adjusted to match that of the passively moved left arm. As a consequence, the absolute difference between the velocity of the right and left arms (defined as the normalized velocity) was lower when the left arm was passively moved than when it was static (see Fig. 4). This effect was confirmed in an ANOVA; for the study population as a whole, the mean normalized velocity of the Kohnstamm phenomenon was significantly lower during the passive displacement condition than in the static condition, regardless of the vision condition (i.e. there was a main effect of the left arm condition, $\left.F(1,11)=108.4, \quad p<.01, \quad \eta_{p}^{2}=.56\right)$. In contrast, a significant effect of vision was not observed $(F(1,11)<1, p=.89)$ and there was no significant interaction between vision and the left arm condition $(F(1,11)<1, p=.64)$. Therefore, the velocity of the Kohnstamm phenomenon was similar in the mirror and no-mirror vision conditions, regardless of whether the left arm was static or was moved passively.

\section{DISCUSSION OF EXPERIMENT 1}

The results of Experiment 1 showed that the velocity of the Kohnstamm phenomenon in the right arm tended to be adjusted to match the velocity of the passively moved left arm. Participants in whom the Kohnstamm phenomenon in the right arm was faster than $4 \% \mathrm{~s}$ tended to slow down when the left arm was moved passively, whereas participants in whom the Kohnstamm phenomenon in the right arm was slower than $4 \%$ sended to speed up. However, the coupling between the two arms did not depend on the visual 


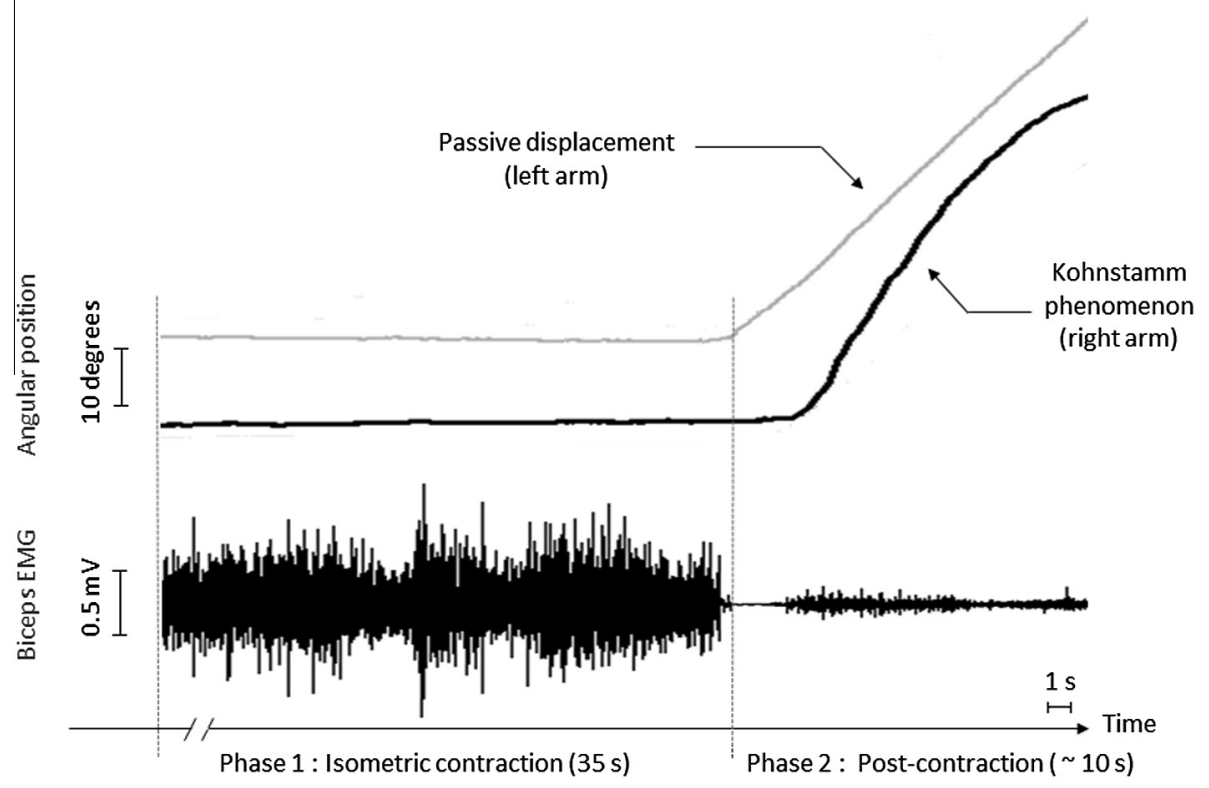

Fig. 2. A representative trial during Experiment 1. The upper (gray) line shows the angular position of the left arm held by the motorized manipulandum (moving into flexion). The middle (black) line shows the angular position of the right arm and depicts the Kohnstamm phenomenon. Muscle (EMG) activity of the right biceps is shown in the lower part of the figure. Low-intensity EMG activity occurs $1-2 s$ after the cessation of isometric contraction.

Table 1. (Results of Experiment 1.) Mean velocities and mean normalized velocities (relative to $4 \% \mathrm{~s}$ ) of the right arm (subject to the Kohnstamm phenomenon) under the four experimental conditions (mirror/no mirror $\times$ passive displacement/static)

\begin{tabular}{|c|c|c|c|c|c|c|c|c|}
\hline & \multicolumn{4}{|c|}{ Passive displacement } & \multicolumn{4}{|l|}{ Static } \\
\hline & \multicolumn{2}{|l|}{ Mirror } & \multicolumn{2}{|c|}{ No mirror } & \multicolumn{2}{|l|}{ Mirror } & \multicolumn{2}{|c|}{ No mirror } \\
\hline & Mean & SD & Mean & SD & Mean & SD & Mean & SD \\
\hline Velocity $(\% / s)$ & 5.8 & 3.4 & 5.7 & 2.7 & 7.9 & 7.5 & 7.5 & 5.2 \\
\hline Normalized velocity $(\% / s)$ & 2.9 & 2.7 & 2.7 & 1.7 & 6.1 & 5.9 & 5.3 & 3.4 \\
\hline
\end{tabular}

condition; there was no difference between the mirror and no-mirror conditions and the velocity matching in these two visual conditions correlated significantly. Therefore, passive displacement of the left arm (rather than mirror reflection, which is often not dissociated from displacement in the mirror paradigm) was probably the key factor modulating the velocity of involuntary movement of the right arm.

Passive displacement of the arm activates joint receptors, primary afferents of the muscle spindles and also cutaneous afferents. The primary and cutaneous afferents are particularly involved in kinesthesia (Teasdale et al., 1993; Blouin et al., 1995; Refshauge and Fitzpatrick, 1995; Collins and Prochazka, 1996; Day and Cole, 2002; Proske and Gandevia, 2012; Blanchard et al., 2013). Hence, stimulating primary spindle endings (la fibers) by applying vibration to a muscle-tendon system may be interpreted by the central nervous system as an elongation of that muscle and can therefore induce either motor effects (Goodwin et al., 1972; Romaiguere et al., 1991) or an illusory sensation of joint displacement (also referred to as the vibratory illusion (Goodwin et al.,
1972; Gilhodes et al., 1986; Ceyte et al., 2007; Guerraz et al., 2012)). Moreover, applying a sustained muscle vibration for $30 \mathrm{~s}$ has also been found to induce long-lasting post-contraction of the previously stimulated muscle (Gilhodes et al., 1992; Duclos et al., 2007). The latter researchers suggested that the motor post-effects following isometric contraction or vibratory stimulation are both related to muscle proprioceptors. Indeed, sustained isometric voluntary contraction and mechanical vibration are both known to change the activity of muscle spindle endings in the stimulated muscle (Vedel and Roll, 1982; Edin and Vallbo, 1990).

However, it has never been shown that the proprioceptive input from one limb can influence motor post-effects in the contralateral limb. Hence, we designed Experiment 2 in order to simulate passive left arm displacement (via the application of vibration while the participant's arm remained static) and to test whether this simulated displacement influenced the Kohnstamm phenomenon in the right arm (as actual passive displacement does). Given that provision of mirror feedback does not add to the velocity adjustment 


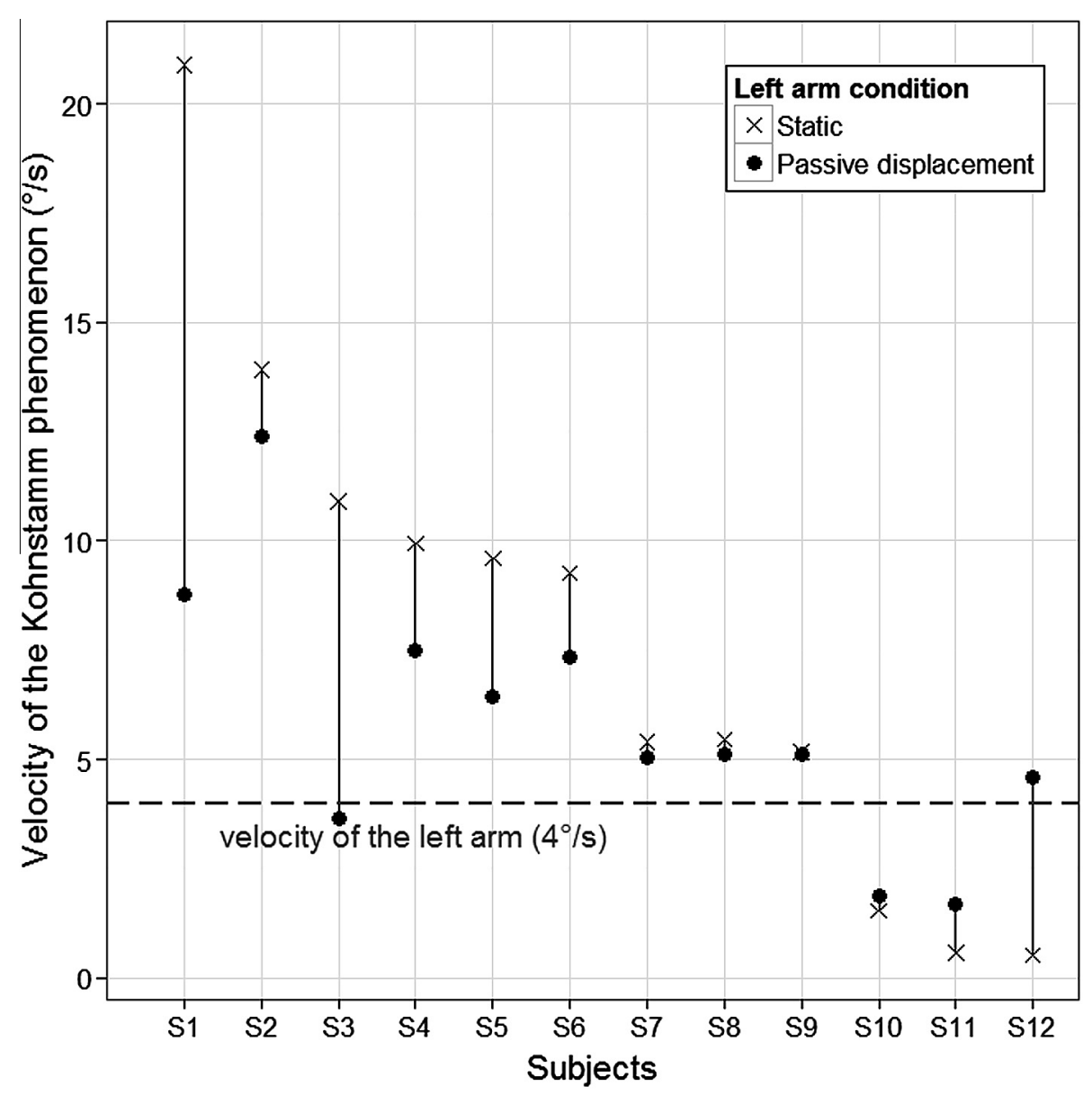

Fig. 3. Individual values of the Kohnstamm phenomenon (velocity) in the right arm when the left was static (crosses) or passively displaced (circles). Data from mirror and no-mirror trials were combined. The horizontal (dashed) line represents the velocity of the passive displacement of the left arm.

of the Kohnstamm phenomenon observed in condition of passive displacement in Experiment 1, and to avoid increasing the level fatigue by multiplying experimental conditions, Experiment 2 was performed only under eyes-closed conditions.

\section{EXPERIMENTAL PROCEDURES OF EXPERIMENT 2}

\section{Participants}

Nine right-handed participants (6 females and 3 males; mean (SD) age $=22.7$ (3.7) years) took part in Experiment 2. Nine of the 13 tested participants were sensitive to the Kohnstamm phenomenon on first application and therefore took part in Experiment 2. One of the participants had already taken part in Experiment 1. None of the nine participants had a history of visual, proprioceptive or neuromuscular disease, and all provided their prior, written, informed consent to participation in the experiment.

\section{Material}

The material was similar to that used in Experiment 1 , except that the left manipulandum was not motorized.
Simulated displacement of the left arm in Experiment 2 was achieved with an electromechanical vibratory apparatus (Innovative Technology, Marseille, France). The vibratory apparatus was positioned directly on the belly of the left triceps.

\section{Procedure}

Measurement of the "illusory velocity" as a function of the vibration frequency. In preliminary trials, we evaluated the participants' sensitivity to the vibratory illusion. The vibration frequency was either low $(25 \mathrm{~Hz})$, medium $(50 \mathrm{~Hz})$ or high $(75 \mathrm{~Hz})$. The two arms were positioned on the manipulanda at $30^{\circ}$ to the horizontal. Vibration was applied to the left triceps for $15 \mathrm{~s}$. The participants were then required to reproduce (with the same arm) the velocity of the (illusory) displacement that they had perceived during the vibration. Two vibration-free sham trials were also performed. The right arm was not used for reproduction of the "illusory velocity", so as to avoid confusion with experimental trials. Participants were also required to close their eyes in the preliminary trials. Two trials were performed for 


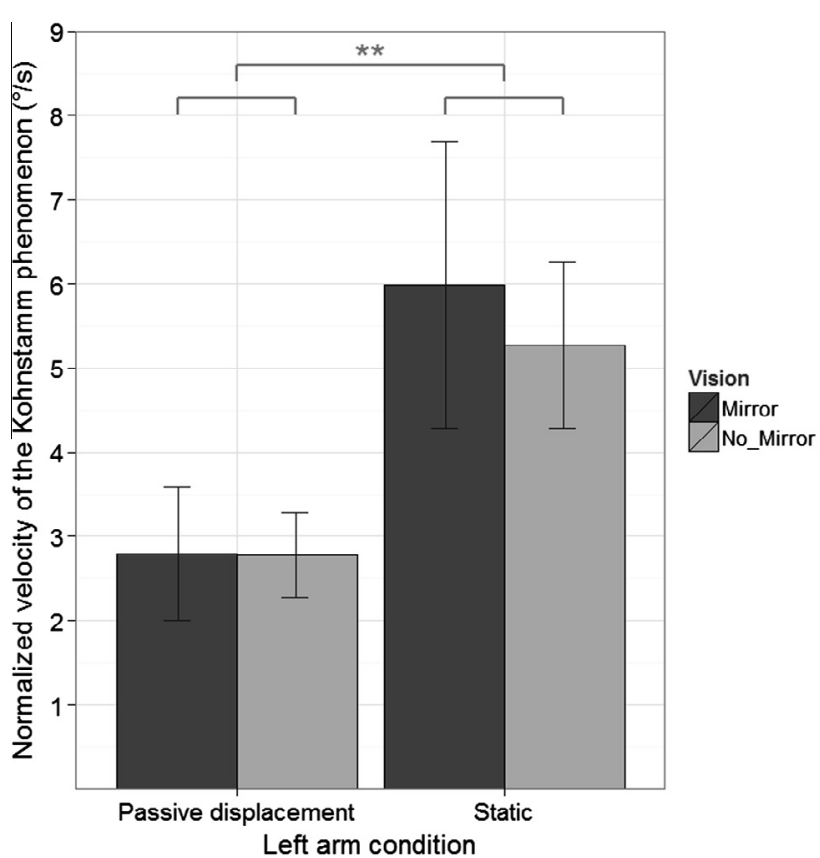

Fig. 4. The mean normalized velocity of the Kohnstamm phenomenon. A value of zero indicates that the right arm moves at $4 \%$ s (i.e. the velocity of the passive displacement of the left arm). Error bars correspond to the standard errors. The asterisks indicate a statistically significant difference $\left(^{* *}=p<.01\right)$.

each vibration condition, giving a total of eight (in random order).

Measurement of the Kohnstamm phenomenon. The Kohnstamm phenomenon was evoked in the same way as in Experiment 1. Using the right arm, the participants exerted a constant, isometric force (at $40 \%$ of the MVC) for $35 \mathrm{~s}$. Just before they stopped pulling on the lever, the participant was told to close his/her eyes and the vibrator was turned on (at 25,50 or $75 \mathrm{~Hz}$ ) until the end of the trial. The vibration-induced, simulated triceps stretch applied to the left arm was therefore congruent with the direction of the involuntary displacement (i.e. Kohnstamm phenomenon) following sustained contraction of the right arm. A fourth condition (consisting in turning off the vibrator) was used as the reference condition in order to normalize the results of the trials with vibration at 25,50 and $75 \mathrm{~Hz}$. Each condition was repeated four times in pseudo-random order, giving a total of 16 trials per participant in a within-subjects design.

\section{Data analysis}

Velocity of the right and left arm displacements. The velocity (in $\%$ ) of arm displacement was measured in the same way as in Experiment 1. However, in contrast to Experiment 1 (in which the left arm was subjected to real displacements), it was not possible to evaluate whether the vibration-induced, simulated movement in each trial in Experiment 2 was faster or slower than the Kohnstamm phenomenon measured for the right arm. Indeed, due to inter-individual differences in vibration sensitivity, the frequency of vibration (and the related primary nerve ending discharge rates) does not correspond strictly to the estimated illusory velocity (Roll et al., 1989; Gilhodes et al., 1992). The mean angular velocity of the Kohnstamm phenomenon in the three vibration conditions $(25,50$ and $75 \mathrm{~Hz})$ was therefore normalized by subtracting the mean angular velocity recorded in the reference condition (i.e. in the absence of vibration). Hence, a positive value indicated that the Kohnstamm phenomenon was faster in the vibration conditions than in the reference condition. Conversely, a negative value indicated that the Kohnstamm phenomenon was slower in the vibration conditions than in the reference condition.

Integrated EMG activity. As in Experiment 1, EMG activity during the contraction phase was analyzed. The iEMG activities measured during the contraction period for the biceps (mean (SD) $=30$ (1.8) \% of MVC, $F<1$, $p>.05)$ and the triceps (mean (SD) $=17(0.6) \%$ of MVC, $F<1, p>.05)$ were similar under the various experimental conditions.

\section{Statistics}

Kinematic data were assessed in a one-way, repeatedmeasures ANOVA with the three vibration frequencies $(25,50$ and $75 \mathrm{~Hz})$. The reported values were HuynhFeldt corrected and post hoc tests were performed using a Holm correction for multiple comparisons. Pearson's correlation coefficient was used to test the linear relationship between the effect of increasing vibration frequency on the velocity of the Kohnstamm phenomenon and on vibratory illusions. The threshold for statistical significance was set to $p<.05$.

\section{RESULTS OF EXPERIMENT 2}

\section{The "illusory velocity" as a function of the vibration frequency}

The illusions of movement evoked by the different vibration conditions were measured (by asking participants to reproduce what they felt during vibration with the same arm) in each individual prior to the experimental session. As mentioned above, the application of vibration to the left triceps evoked an illusion of flexion, the velocity of which was related to the frequency of vibration. Limited or no illusion was reported in the $25-\mathrm{Hz}$ (mean $(\mathrm{SD})=1.8 \quad(3.5) \%$ ) condition, whereas more consistent, "faster" illusory movements were reported in the $50-\mathrm{Hz}$ condition (mean $(\mathrm{SD})=5.8(5.7) \%$ ) and the $75-\mathrm{Hz}$ (mean (SD) $=14$ (11) $\%$ s) condition. An ANOVA analysis confirmed the significant effect of the vibration frequency on illusion's velocity $(F(2,8)=14.1, p<.01)$.

\section{The velocity of the Kohnstamm phenomenon as a function of the vibration frequency}

Shortly after the cessation of muscle contraction, the right forearm flexed slowly and involuntarily. When the data from the different experimental conditions were pooled, 
Table 2. (Results of Experiment 2.) Mean velocities and mean normalized velocities of the right arm (subject to the Kohnstamm phenomenon) at the different vibration frequencies (no vibration, 25,50 , and $75 \mathrm{~Hz}$ )

\begin{tabular}{|c|c|c|c|c|c|c|c|c|}
\hline & \multicolumn{2}{|c|}{ No vibration } & \multicolumn{2}{|c|}{ Low $(25 \mathrm{~Hz})$} & \multicolumn{2}{|c|}{ Medium $(50 \mathrm{~Hz})$} & \multicolumn{2}{|c|}{ High $(75 \mathrm{~Hz})$} \\
\hline & $\overline{\text { Mean }}$ & $\overline{S D}$ & Mean & $\overline{S D}$ & Mean & SD & $\overline{\text { Mean }}$ & $\mathrm{SD}$ \\
\hline Velocity $(\% / s)$ & 5.3 & 3.1 & 4.0 & 4.9 & 4.9 & 6.0 & 7.1 & 7.7 \\
\hline Normalized velocity $(\% / \mathrm{s})$ & - & - & -1.33 & 5.0 & -.33 & 5.2 & 1.7 & 6.3 \\
\hline
\end{tabular}

the mean (SD) velocity of the Kohnstamm phenomenon was $5.1(5.9) \%$ s (Table 2).

\section{The normalized velocity of the Kohnstamm phenomenon as a function of the vibration frequency}

The mean angular velocity of the Kohnstamm phenomenon in the reference condition (i.e. in the absence of vibration) was subtracted from the values measured in the three vibration conditions $(25,50$ and $75 \mathrm{~Hz}$ ). The velocity of the Kohnstamm phenomenon in the 25-, 50- or $75-\mathrm{Hz}$ conditions could be higher (i.e. with positive normalized values) than in the reference condition for some participants but lower (i.e. with negative normalized values) for others (see individual data in Fig. 5).

As can be seen in Fig. 5, the normalized velocity of the right arm increased with the vibration frequency applied to the other arm in all participants (see also Fig. 6 for averaged data). This increase was confirmed in an ANOVA $\left(F(2,16)=9.69, p<.01, \eta_{\mathrm{p}}^{2}=.55\right)$. Post hoc analyses revealed significant differences between the $25-$ and $75-\mathrm{Hz}$ conditions $(p<.01)$ and between the 50 and $75-\mathrm{Hz}$ conditions $(p<.05)$. The difference between the 25 and $50 \mathrm{~Hz}$ did not achieve statistical significance $(p=.19)$. No movement occurred in the left arm during vibratory stimulation (as checked with the affixed positional sensor).

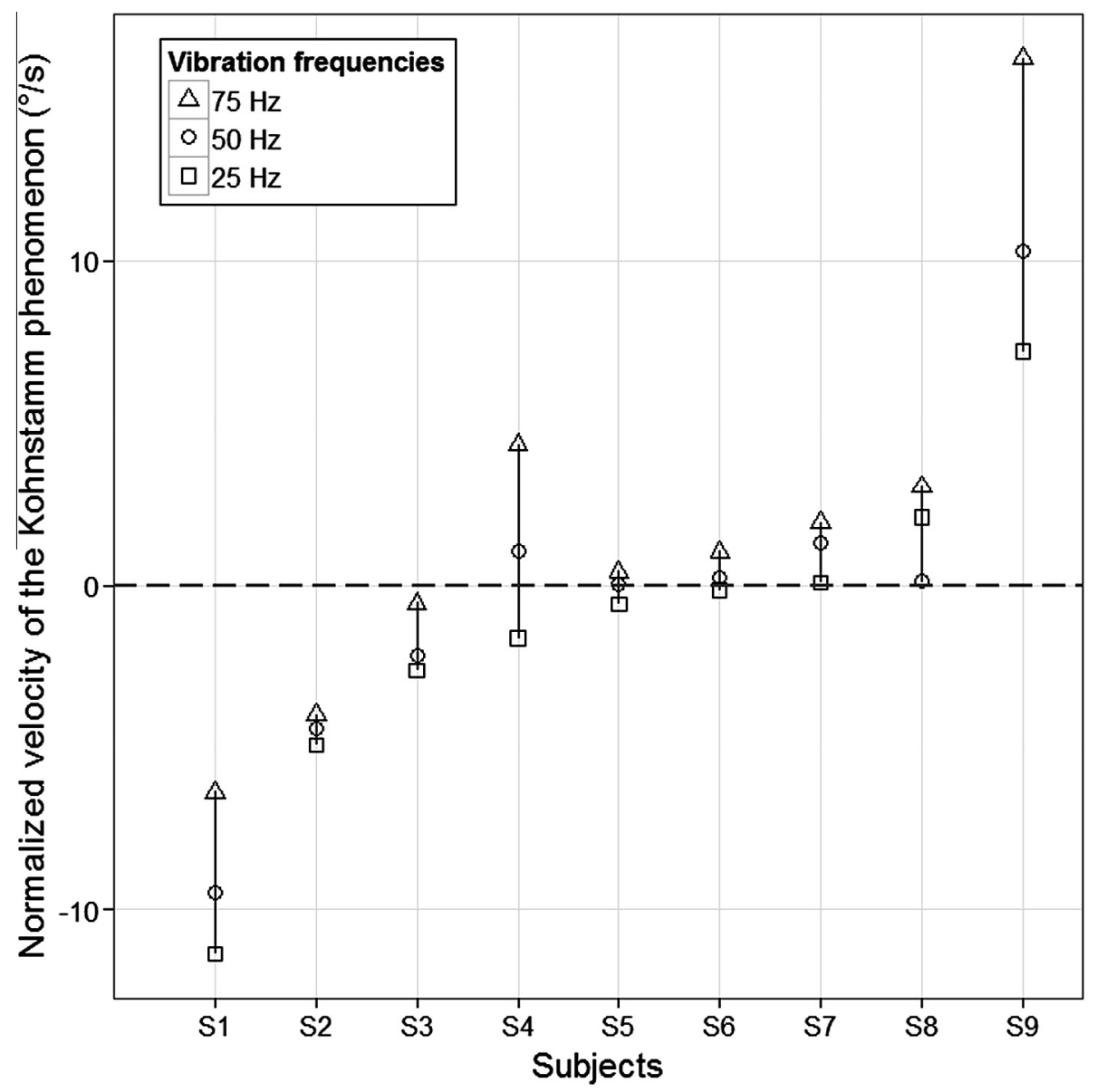

Fig. 5. Individual values of the normalized velocity of the right arm (subject to the Kohnstamm phenomenon) at each vibration frequency. A positive normalized value indicates that the Kohnstamm phenomenon was faster in the given vibration frequency than in the reference condition, whereas a negative normalized value indicates that it was slower. 


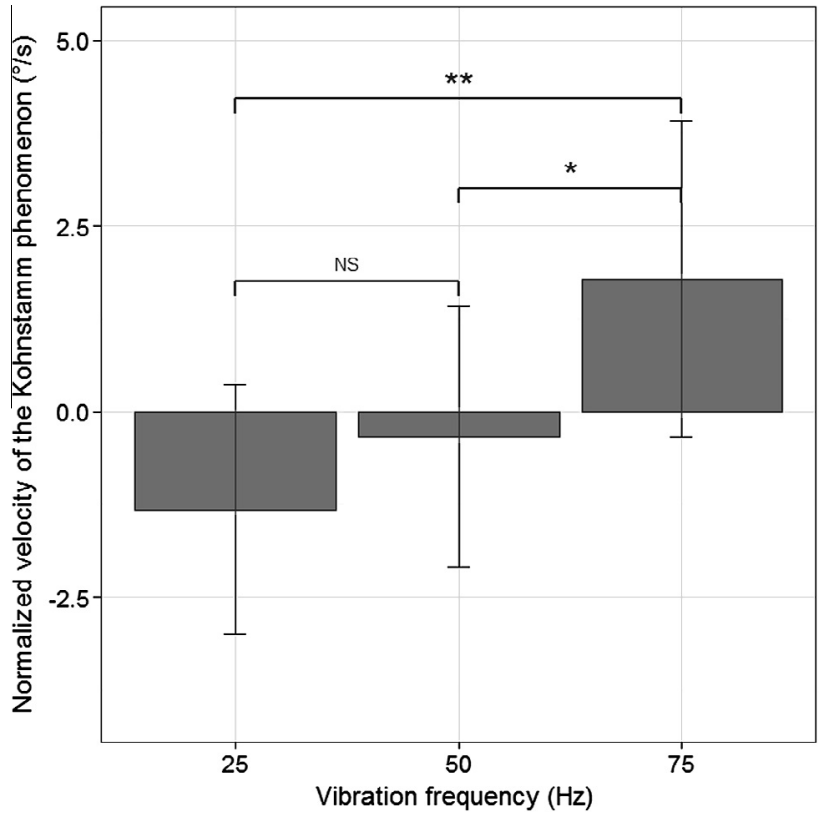

Fig. 6. The mean normalized velocity of the Kohnstamm phenomenon in the three vibration frequencies. Error bars correspond to the standard error. The asterisks indicate a statistically significant difference $\left({ }^{*}=p<.05,{ }^{*}=p<.01\right.$; NS $=$ non-significant).

\section{Relationship between the velocity of vibratory illusion and the velocity of Kohnstamm phenomenon as a function of the vibration frequency}

Although the velocity of the Kohnstamm phenomenon in all participants rose as the vibration frequency increased from 25 to $75 \mathrm{~Hz}$, the magnitude of the increase varied markedly

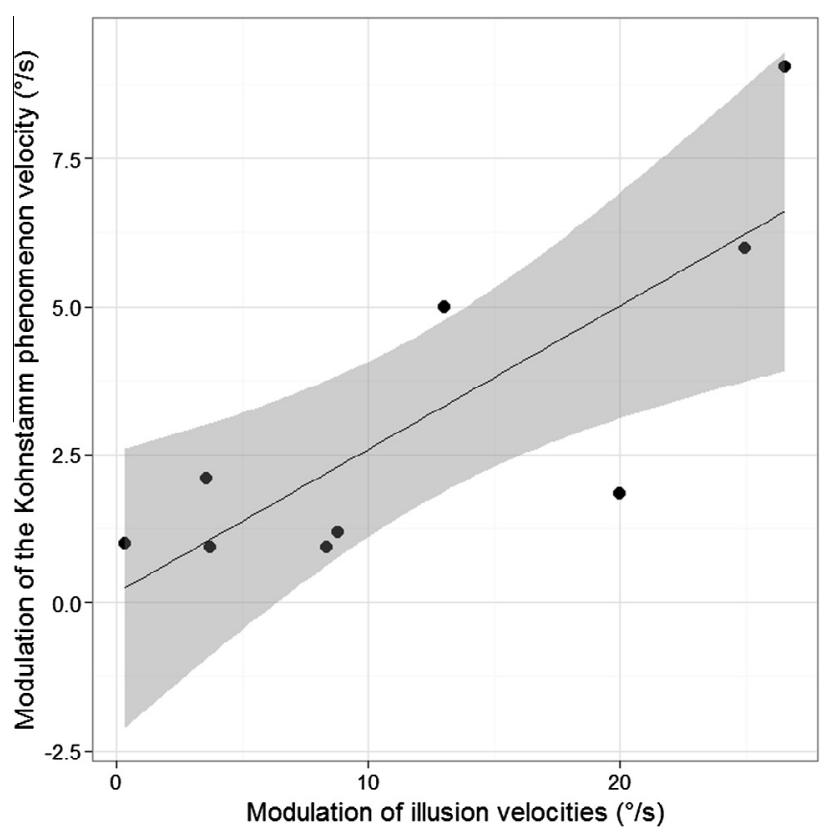

Fig. 7. The relationship between the modulations of the velocity of the Kohnstamm phenomenon and of the velocity of illusory displacement when going from 25 to $75 \mathrm{~Hz}$. The shaded area corresponds to the regression line's $95 \%$ confidence interval. from one participant to another (range: $0.93-9.1 \% \mathrm{~s}$ ). A correlation analysis (Fig. 7) revealed that this increase in the velocity of the Kohnstamm phenomenon was strongly and positively related to the increase in the velocity of vibratory illusion (from 25 to $75 \mathrm{~Hz})(r=.81 p<.01$ ).

\section{DISCUSSION OF EXPERIMENT 2}

Simulated flexion of the left arm was found to modulate the velocity of the Kohnstamm phenomenon in the other arm; the higher the vibration frequency (going from 25 to $75 \mathrm{~Hz}$ ), the higher the velocity of the Kohnstamm phenomenon. Our results also revealed that the increase in the velocity of the Kohnstamm phenomenon (going from 25 to $75 \mathrm{~Hz}$ ) occurred in all individuals participating in Experiment 2 (albeit to a variable extent), which thus attests to the robustness of this effect. Interindividual differences in sensitivity to muscle spindles stimulation by the use of vibration are commonly observed when motor or perceptual effects are concerned (Calvin-Figuière et al., 1999). Interestingly, the increase in the velocity of the Kohnstamm phenomenon correlated strongly and positively $(r=.81)$ with the increase in the velocity of the vibratory illusion (from 25 to $75 \mathrm{~Hz}$ ).

However, it must be recognized that in addition to muscle spindles, golgi tendon organs also respond to tendon or muscle vibration (Burke et al., 1976; Proske and Gandevia, 2012), though to a much lesser extent in relaxed muscles as compared to tensed muscles (Fallon and Macefield, 2007). Those organs largely involved in the sense of force (see also the involvement of muscle spindles in that sense; Luu et al., 2011) can be in turn an accessory source of information in limb position (Worringham and Stelmach, 1985). In the same vein, the vibration frequency used in the present experiment (from 25 to $75 \mathrm{~Hz}$ ) also activates cutaneous afferents such as Meissner corpuscles (that respond to $10-80 \mathrm{~Hz}$ vibration; Talbot et al., 1968) or Pacinian corpuscles (that respond to vibration at high frequencies, $80-450 \mathrm{~Hz}$; Talbot et al., 1968). As suggested by Weerakkody et al. (2007) and Blanchard et al. (2011), those cutaneous signals are likely integrated with that from muscles spindles in position and movement senses. The involvement of tendon and cutaneous signals in the present experiments can therefore not be fully excluded.

To conclude, Experiment 2 showed that simulated movement of one arm impacts involuntary movements (i.e. Kohnstamm phenomenon) of the other arm - just as actual passive movement does (Experiment 1). Artificial stimulation of the afferent receptors of one arm is therefore enough to induce bimanual coupling, that is, a strong coupling between the two hands constrained in spatial or temporal terms (Swinnen, 2002).

\section{GENERAL DISCUSSION}

\section{Mirror vision has a limited impact on the Kohnstamm phenomenon}

It has been suggested that mirror reflection of the movement of one hand influences the motor output of 
the other (hidden) hand in voluntary bimanual coordination tasks (Franz and Packman, 2004). Franz and Packman (2004) investigated the effect of mirror reflection of circle-drawing movements of one hand on the motor output of the other hand. When only one hand was visible, the visible hand drew circles with a larger radius than the hidden hand. When two hands were visible (either the right and left hand together or the right hand and its reflection in the mirror), there was no difference in radius between the hands. Franz and Packman therefore suggested that visual symmetry of apparent, bimanual movement in the mirror condition enhanced the spatial coupling of the two hands much as actual vision of the two hands does (Franz and Packman, 2004). However, Metral et al. (2014) used a similar paradigm to show that motor performance with mirror vision was no better than with the eyes closed. In line with Metral et al.'s results, our present data failed to show a significant impact of mirror vision on involuntary motor control. In contrast, passive displacement of one arm markedly influenced involuntary displacement of the other arm (Kohnstamm phenomenon). These results suggest that although mirror reflection of one arm can give the illusion of symmetrical bimanual movements, it seems less effective in modulating both voluntary and involuntary motor control.

However, while our results showed that proprioceptive inputs from one arm influenced post-contraction movements of the other arm, and that provision of mirror feedback does not add to this effect (Experiment 1 ), they do not rule out that mirror vision would not also influence post-contraction movements, if it were supplied independent of proprioceptive inputs (which was not the case in our study nor in the mirror paradigm in general). If proprioceptive inputs can easily be isolated and their impact on motor control evaluated, as it were in Experiment 1 and 2, visual inputs are more difficult to isolate. Although not considered in the present study for technical or clinical reasons, different paradigms might be of particular relevance to evaluate the impact of visual inputs in isolation. Among those, virtual reality might be the most relevant tool. It would for instance provide healthy participants with visual inputs related to arm movement in the absence of proprioceptive inputs. Patients deprived of proprioceptive of one arm (brachial plexus lesion or ischemia) could also be considered for that purpose. Despite this limitation of our experimental paradigm to evaluate the impact of visual inputs in isolation, the absence of additional effect of mirror inputs on involuntary motor control in healthy participants, echoes Rothgangel et al.,'s recent review (2011) that has questioned whether mirror therapy is better than bimanual coupling in recovery from hemiparesis.

\section{Adjustment of the Kohnstamm phenomenon for real or simulated displacement of the contralateral arm: bimanual coupling}

When performing voluntary bimanual movements, there is a natural trend toward the symmetric motion of both arms (Mayston et al., 1999; Swinnen, 2002; Galléa et al., 2011). Bilateral symmetrical motor activity may represent the central nervous system's default operating mode (Swinnen, 2002). This symmetrical feature of motor behavior has also been reported for involuntary movements. Indeed, Craske and Craske (1986) showed that the Kohnstamm phenomenon in one arm was modulated by the Kohnstamm phenomenon, in the opposite direction, in the other arm. Our present results show for the first time that bimanual coupling also appears to operate in conditions of actual or simulated displacement of the other arm. Indeed, the velocity of the Kohnstamm phenomenon was adjusted to match that of the passive displacement (Experiment 1) or simulated displacement (Experiment 2) of the other arm. As long as discrete spatial movements are concerned, motor commands (involved in either voluntary or involuntary movements) might therefore not be key elements in bimanual coupling.

It is particularly interesting to note that afferent signals from one arm have also been shown to determine the perceived position and movement of the other arm. Izumizaki et al. (2010) and then Hakuta et al. (2014) showed that the kinaesthesic illusions generated by vibration in one arm can be modified by either passive displacement or vibration-induced simulated displacement of the other arm. Taken as a whole, these results indicate that both motor activity and the perception of position and movement of one arm are dependent (at least to some extent) on afferent signals originating from the other arm.

\section{Origin of the bimanual coupling evoked by real or simulated displacement of one arm}

The present results raise the question of the level of movement representation at which this interaction or crossed effect occurs. Afferent inputs associated with the passive or simulated (by vibration) displacement of the left arm could exert crossed effects at a cortical level or subcortically, at propriospinal or segmental levels. Observation of the motor performances of a patient having undergone progressive resection of the corpus callosum prompted Eliassen et al. (1999) to suggest that spatial coupling in bimanual coordination reflects communication between parietal regions, that is to say between regions that have a role in planning/representation rather than the motor execution of spatial trajectories. Interestingly, transcranial magnetic stimulation of the posterior parietal cortex modulates the excitability of the contralateral primary motor cortex (Koch et al., 2009). In this respect, projections toward the parietal cortices from muscle spindles that are stimulated during both passive and simulated movements might be sufficient to facilitate automatic, bimanual coordination. However, passive or simulated displacement of a single arm activates motor areas as well as parietal cortices on both sides of the brain (Mima et al., 1999; Romaiguère et al., 2003; Naito et al., 2005; Kavounoudias et al., 2008; Formaggio et al., 2013). For instance, Romaiguère et al. (2003) showed that the vibration-induced perception of illusory movements activates the contralateral primary motor cortex, the bilateral premotor and parietal cortices, the bilateral supplementary motor areas, the bilateral cingulate motor areas and the ipsilateral middle and inferior frontal 
gyri. In contrast, by recording blood-oxygen-level-dependent (BOLD) responses after $30 \mathrm{~s}$ of sustained, isometric contraction of the wrist extensor muscles, Duclos et al. (2007) observed the bilateral activation of a broad sensorimotor network (including the primary somatosensory, premotor, inferior parietal and cingulate motor cortices) as well as contralateral activation of the primary motor cortex. Similarly, Formaggio and collaborators (2013) evidenced bilateral activation of sensorimotor cortices following the passive displacement of one arm (particularly for the non-dominant arm). Hence, the bimanual coupling observed in the present experiments might result from activation of the parietal and/or motor cortices during the simultaneous occurrence of the Kohnstamm phenomenon in the right arm and passive or simulated movement of the left arm.

As mentioned above, afferent inputs associated with the passive or simulated displacement could also exert crossed effects subcortically. Several crossed effects between the right and left limbs via spinal pathways in response to afferent stimulation have been described, though their precise actions (acting either directly onto motoneurons or indirectly via excitatory or inhibitory interneurons) are often debated (Mezzarane et al., 2012). For instance, passive cycling movements (Collins et al., 1993) and conditioning mechanical stimulation (single tap) of one leg (Koceja and Kamen, 1992) have been shown to induce $\mathrm{H}$-reflex inhibition on the contralateral leg. In both cases, the contralateral inhibition is supposed to be mediated by primary endings. Cutaneous (Aggelopoulos and Edgley, 1995) and tendinous (Frigon and Rossignol, 2008) activations, which might also be activated by either passive or simulated displacement in Experiments 1 and 2, are also at the origin of crossed effects. Although speculative, the involvement of such cross effects which can either facilitate or inhibit the Kohnstamm phenomenon, in the present experiments cannot be fully discarded.

\section{CONCLUSIONS}

It has been suggested that mirror reflection of the movement of one hand influences the motor output of the other (hidden) hand. This tool is often used in clinical rehabilitation. However, the mirror paradigm's advantage over bimanual coupling is not fully convincing. The present study is the first to show that displacement of the arm (which is a confounding factor with visual reflection in the mirror paradigm) is the key element influencing motor behavior of the contralateral arm.

\section{AUTHOR CONTRIBUTIONS}

All the authors participated to the conception, design interpretation of the data. $\mathrm{CB}, \mathrm{MM}, \mathrm{MC}$ and $\mathrm{MG}$ conducted the studies. The original draft was prepared by $C B$ and $M G$ but the six authors critically revised the manuscript before approving the final version.

\section{COMPETING INTERESTS}

None of the authors have any conflicts of interests.

\section{FUNDING}

The work was supported through funding from the University of Savoie (France).

Acknowledgments-We thank Tina Rochette for her help in data collection and Dr David Fraser (Biotech Communication, Damery, France) for improving the manuscript's English.

\section{REFERENCES}

Aggelopoulos NC, Edgley SA (1995) Segmental localisation of the relays mediating crossed inhibition of hindlimb motoneurones from group II afferents in the anaesthetized cat spinal cord. Neurosci Lett 185:60-64.

Blanchard C, Roll R, Roll JP, Kavounoudias A (2011) Combined contribution of tactile and proprioceptive feedback to hand movement perception. Brain Res 1382:219-229.

Blanchard C, Roll R, Roll JP, Kavounoudias A (2013) Differential contributions of vision, touch and muscle proprioception to the coding of hand movements. PloS One 8:e62475.

Blouin J, Vercher JL, Gauthier GM, Paillard J, Bard C, Lamarre Y (1995) Perception of passive whole-body rotations in the absence of neck and body proprioception. J Neurophysiol 74:2216-2219.

Bock O, Pipereit K, Mierau A (2007) A method to reversibly degrade proprioceptive feedback in research on human motor control. J Neurosci Methods 160:246-250.

Burke D, Hagbarth KE, Lofstedt L, Wallin BG (1976) The responses of human muscle spindle endings to vibration of non-contracting muscles. J Physiol 261:673-693.

Calvin-Figuière S, Romaiguère P, Gilhodes JC, Roll JP (1999) Antagonist motor responses correlate with kinesthetic illusions induced by tendon vibration. Exp Brain Res 124:342-350.

Ceyte H, Cian C, Zory R, Barraud PA, Roux A, Guerraz M (2007) Effect of Achilles tendon vibration on postural orientation. Neurosci Lett 416:71-75.

Collins DF, Prochazka A (1996) Movement illusions evoked by ensemble cutaneous input from the dorsum of the human hand. J Physiol 496:857-871.

Collins DF, Mcllroy WE, Brooke JD (1993) Contralateral inhibition of soleus $\mathrm{H}$ reflexes with different velocities of passive movement of the opposite leg. Brain Res 603:96-101.

Craske B, Craske JD (1986) Oscillator mechanisms in the human motor system: investigating their properties using the aftercontraction effect. J Mot Behav 18:117-145.

Day BL, Cole J (2002) Vestibular-evoked postural responses in the absence of somatosensory information. Brain Res 125:2081-2088.

Dohle C, Püllen J, Nakaten A, Küst J, Rietz C, Karbe H (2009) Mirror therapy promotes recovery from severe hemiparesis: a randomized controlled trial. Neurorehabil Neural Repair 23:209-217.

Duclos C, Roll R, Kavounoudias A, Roll JP (2007) Cerebral correlates of the "Kohnstamm phenomenon": an fMRI study. Neuroimage 34:774-783.

Edin BB, Vallbo AB (1990) Muscle afferent responses to isometric contractions and relaxations in humans. J Neurophysiol 63:1307-1313

Eliassen JC, Baynes K, Gazzaniga MS (1999) Direction information coordinated via the posterior third of the corpus callosum during bimanual movements. Exp Brain Res 128:573-577.

Fallon JB, Macefield VG (2007) Vibration sensitivity of human muscle spindles and Golgi tendon organs. Muscle Nerve 36:21-29.

Formaggio E, Storti SF, Boscolo Galazzo I, Gandolfi M, Geroin C, Smania N, Spezia L, Waldner A, Fiaschi A, Manganotti P (2013) 
Modulation of event-related desynchronization in robot-assisted hand performance: brain oscillatory changes in active, passive and imagined movements. J Neuroeng Rehabil 26:10-24.

Franz EA, Packman T (2004) Fooling the brain into thinking it sees both hands moving enhances bimanual spatial coupling. Exp Brain Res 157:174-180.

Frigon A, Rossignol S (2008) Short-latency crossed inhibitory responses in extensor muscles during locomotion in the cat. J Neurophysiol 99:989-998.

Galléa C, Popa T, Billot S, Méneret A, Depienne C, Roze E (2011) Congenital mirror movements: a clue to understanding bimanual motor control. J Neurol 258:1911-1919.

Ghafouri M, Thullier F, Gurfinkel VS, Lestienne FG (1998) Muscular after-contraction and ongoing postural reactions in standing and sitting humans. Neurosci Lett 250:61-65.

Gilhodes JC, Roll JP, Tardy-Gervet MF (1986) Perceptual and motor effects of agonist-antagonist muscle vibration in man. Exp Brain Res 61:395-402.

Gilhodes JC, Gurfinkel VS, Roll JP (1992) Role of la muscle spindle afferents in post-contraction and post-vibration motor effect genesis. Neurosci Lett 135:247-251.

Goodwin GM, McCloskey DI, Matthews PB (1972) The contribution of muscle afferents to kinaesthesia shown by vibration induced illusions of movement and by the effects of paralysing joint afferents. Brain Res 95:705-748.

Gregory JE, Morgan DL, Proske U (1987) Changes in size of the stretch reflex of cat and man attributed to aftereffects in muscle spindles. J Neurophysiol 58:628-640.

Guerraz M, Provost S, Narison R, Brugnon A, Virolle S, Bresciani JP (2012) Integration of visual and proprioceptive afferents in kinesthesia. Neurosci Lett 223:258-268.

Gurfinkel VS, Levick YS (1989) Immediate and remote postactivation effects in the human motor system. Neurophysiology 21:343-351.

Gurfinkel VS, Levick YS (1991) Perceptual and automatic aspects of the postural body scheme. In: Paillard Jacques, editor. Brain and space. New York, NY, US: Oxford University Press. p. 147-162. $\mathrm{xi}, 499 \mathrm{pp}$.

Hagbarth KE, Nordin M (1998) Postural after-contractions in man attributed to muscle spindle thixotropy. J Physiol 506:875-883.

Hakuta N, Izumizaki M, Kigawa K, Murai N, Atsumi T, Homma I (2014) Proprioceptive illusions created by vibration of one arm are altered by vibrating the other arm. Exp Brain Res 232:2197-2206.

Holmes NP, Crozier G, Spence C (2004) When mirrors lie: "visual capture" of arm position impairs reaching performance. Cogn Affect Behav Neurosci 4:193-200.

Hutton RS, Kaiya K, Suzuki S, Watanabe S (1987) Post-contraction errors in human force production are reduced by muscle stretch. J Physiol 393:247-259.

Ivanenko YP, Wright WG, Gurfinkel VS, Horak F, Cordo P (2006) Interaction of involuntary post-contraction activity with locomotor movements. Exp Brain Res 169:255-260.

Izumizaki M, Tsuge M, Akai L, Proske U, Homma I (2010) The illusion of changed position and movement from vibrating one arm is altered by vision or movement of the other arm. J Physiol 588:2789-2800.

Koceja DM, Kamen G (1992) Contralateral influences on triceps surae motoneuron excitability. Electroencephalogr Clin Neurophysiol 85:177-182.

Kavounoudias A, Roll JP, Anton JL, Nazarian B, Roth M, Roll R (2008) Proprio-tactile integration for kinesthetic perception: an fMRI study. Neuropsychologia 46:567-575.

Koch G, Ruge D, Cheeran B, Fernandez Del Olmo M, Pecchioli C, Marconi B, Versace V, Lo Gerfo E, Torriero S, Oliveri M, Caltagirone C, Rothwell JC (2009) TMS activation of interhemispheric pathways between the posterior parietal cortex and the contralateral motor cortex. J Physiol 587:4281-4292.

Kohnstamm O (1915) Demonstration einer katatonieartigen erscheinung beim gesunden (katatonusversuch). Neurol Zentral BI 34S:290-291.
Luu BL, Day BL, Cole JD, Fitzpatrick RC (2011) The fusimotor and reafferent origin of the sense of force and weight. J Physiol 589:3135-3147.

Mayston MJ, Harrison LM, Stephens JA (1999) A neurophysiological study of mirror movements in adults and children. Ann Neurol 45:583-594.

Mercier C, Sirigu A (2009) Training with virtual visual feedback to alleviate phantom limb pain. Neurorehabil Neural Repair 23:587-594.

Metral M, Blettery B, Bresciani JP, Luyat M, Guerraz M (2013) Trying to move your unseen static arm modulates visually-evoked kinesthetic illusion. PloS One:e80360.

Metral M, Guinot M, Bresciani JP, Luyat M, Roulin JL, Guerraz M (2014) Bimanual coordination with three hands! Is the mirror hand of any help? Neuropsychologia 52:11-18.

Mezzarane RA, Kohn AF, Couto-Roldan E, Martinez L, Flores A, Manjarrez E (2012) Absence of effects of contralateral group I muscle afferents on presynaptic inhibition of la terminals in humans and cats. J Neurophysiol 108:1176-1185.

Mima T, Sadato N, Yazawa S, Hanakawa T, Fukuyama H, Yonekura $Y$, Shibasaki $H$ (1999) Brain structures related to active and passive finger movements in man. Brain Res 122:1989-1997.

Naito E, Roland PE, Grefkes C, Choi HJ, Eickhoff S, Geyer S, Zilles $\mathrm{K}$, Ehrsson HH (2005) Dominance of the right hemisphere and role of area 2 in human kinesthesia. J Neurophysiol 93:1020-1034

Oldfield RC (1971) The assessment and analysis of handedness: the Edinburgh inventory. Neuropsychologia 9:97-113.

Oullier O, Kavounoudias A, Duclos C, Albert F, Roll JP, Roll R (2009) Countering postural posteffects following prolonged exposure to whole-body vibration: a sensorimotor treatment. Eur J Appl Physiol 105:235-245.

Proske U, Gandevia SC (2012) The proprioceptive senses: their roles in signaling body shape, body position and movement, and muscle force. Physiol Rev 92:1651-1697.

Ramachandran VS, Altschuler EL (2009) The use of visual feedback, in particular mirror visual feedback, in restoring brain function. Brain Res 132:1693-1710.

Refshauge KM, Fitzpatrick RC (1995) Perception of movement at the human ankle: effects of leg position. J Physiol 488:243-248.

Romaiguere P, Vedel JP, Azulay JP, Pagni S (1991) Differential activation of motor units in the wrist extensor muscles during the tonic vibration reflex in man. J Physiol 444:645-667.

Romaiguère $\mathrm{P}$, Anton JL, Roth M, Casini L, Roll JP (2003) Motor and parietal cortical areas both underlie kinaesthesia. Brain Res Cogn Brain Res 16:74-82.

Roll JP, Vedel JP, Ribot E (1989) Alteration of proprioceptive messages induced by tendon vibration in man: a microneurographic study. Exp Brain Res 76:213-222.

Rosen B, Lundborg G (2005) Training with a mirror in rehabilitation of the hand. Scand J Plast Reconstr Surg Hand Surg 39:104-108.

Rothgangel AS, Braun SM, Beurskens AJ, Seitz RJ, Wade DT (2011) The clinical aspects of mirror therapy in rehabilitation: a systematic review of the literature. Int J Rehab Res 34:1-13.

Swinnen SP, Puttemans V, Vangheluwe S, Wenderoth N, Levin O, Dounskaia N (2003) Directional interference during bimanual coordination: is interlimb coupling mediated by afferent or efferent processes. Behav Brain Res 139:177-195.

Swinnen SP (2002) Intermanual coordination: from behavioural principals to neural-network interactions. Nat Rev Neurosci 3:348-359.

Talbot WH, Darian-Smith I, Kornhuber HH, Mountcastle VB (1968) The sense of flutter-vibration: comparison of the human capacity with response patterns of mechanoreceptive afferents from the monkey hand. J Neurophysiol 31:301-334.

Teasdale N, Forget R, Bard C, Paillard J, Fleury M, Lamarre Y (1993) The role of proprioceptive information for the production of isometric forces and for handwriting tasks. Acta Psychol (Amst) 82:179-191. 
Vedel JP, Roll JP (1982) Response to pressure and vibration of slowly adapting cutaneous mechanoreceptors in the human foot. Neurosci Lett 31:289-294.

Weerakkody NS, Mahns DA, Taylor JL, Gandevia SC (2007) Impairment of human proprioception by high-frequency cutaneous vibration. J Physiol 581:971-980.

Wells SW (1944) The demonstration of tonic neck and labyrinthine reflexes and positive heliotropic responses in normal human subjects. Neurosci Lett 99:36-37.
Worringham CJ, Stelmach GE (1985) The contribution of gravitational torques to limb position sense. Exp Brain Res 61:38-42.

Zampini M, Moro V, Aglioti SM (2004) Illusory movements of the contralesional hand in patients with body image disorders. $J$ Neurol Neurosurg Psychiatry 75:1626-1628.

(Accepted 11 November 2014)

(Available online 27 November 2014) 